\title{
Influence of Circadian Disruption Associated With Artificial Light at Night on Micturition Patterns in Shift Workers
}

\author{
Su Jin Kim ${ }^{1}$, Jin Wook Kim², Young Sam Cho ${ }^{3}$, Kyung Jin Chung ${ }^{4}$, Hana Yoon ${ }^{5}$, Khae Hawn Kim \\ ${ }^{1}$ Department of Urology, Yonsei University Wonju College of Medicine, Wonju, Korea \\ ${ }^{2}$ Department of Urology, Chung-Ang University College of Medicine, Seoul, Korea \\ ${ }^{3}$ Department of Urology, Sungkyunkwan University School of Medicine, Seoul, Korea \\ ${ }^{4}$ Department of Urology, Gachon University Gil Medical Center, Gachon University of School of Medicine, Incheon, Korea \\ ${ }^{5}$ Department of Urology, Medical Research Center, Ewha Womans University School of Medicine, Seoul, Korea
}

Shift workers often experience problems associated with circadian disruption associated with artificial light at night and nocturia is commonly noted in night-shift workers. Nocturia associated with circadian disruption is due to increased urine production of the kidney and decreased storage function of the bladder. A recent discovery of peripheral clock genes in the bladder and their role in contractile property of the bladder support that micturition is closely related to the circadian rhythm. Moreover, there are clinical studies showed that shift workers more often experienced nocturia due to circadian disruption. However, comparing with other health problems, concerns on nocturia and voiding dysfunction associated with circadian disruption are insufficient. Therefore, further studies about voiding dysfunction associated with the circadian disruption in shift workers are necessary.

Keywords: Artificial light at night; Circadian clock; Urinary bladder; Urination; Nocturia; Sleep

- Fund/Grant Support: This research was supported by Basic Science Research Program through the National Research Foundation of Korea (NRF) funded by the Ministry of Education (2018R1D1A3B07048492). This work was supported (in part) by the Yonsei University Wonju Campus Future-Leading Research Initiative of 2018 (2018-62-0039). This study was supported by the Ministry of Education of the Republic of Korea and the National Research Foundation of Korea (NRF-2017R1A2B2005412). Basic Science Research Program through the National Research Foundation of Korea which was funded by the Ministry of Education supported and funded this work (NRF-2015R 1D 1A 1A 01060982).

- Conflict of Interest: SJK, JWK, YSC, and KHK, members of the Editorial Board of International Neurourology Journal, are the authors of this article. However, they played no role whatsoever in the editorial evaluation of this article or the decision to publish it. Except for that, no potential conflict of interest relevant to this article was reported.

\section{INTRODUCTION}

Artificial light at night (ALAN) changes and contributes to improve human's lifestyle in modern world. Comparing with the past, nowadays, the amount of ALAN is tremendously increased as use of the various new devices such as computers, smartphones, and tablets has been common in daily life. There- fore, people in the present world are exposed to excessive light at night [1-3]. Exposure to ALAN has a harmful influence in human's health and this undesirable effect is associated with the circadian disruption [4].

Several studies reported that ALAN exposure can decrease normal function of cognitive, metabolic, immune, and reproductive systems due to circadian disruption [5-7]. Well-known
Corresponding author: Khae Hawn Kim (iD https://orcid.org/0000-0002-7045-8004 Department of Urology, Gachon University School of Medicine, Gil Medical Center, 21 Namdong-daero 774 beon-gil, Namdong-gu, Incheon 21565, Korea E-mail: kimcho99@gilhospital.com / Tel: +82-32-460-3334 / Fax: +82-32-460-8340 Submitted: December 5, 2019 / Accepted after revision: December 16, 2019
This is an Open Access article distributed under the terms of the Creative Commons Attribution Non-Commercial License (http://creativecommons.org/licenses/by-nc/4.0/) which permits unrestricted non-commercial use, distribution, and reproduction in any medium, provided the original work is properly cited. 
health issues associated with ALAN is obesity and metabolic diseases. A cross sectional study in United Kingdom showed positive correlation between obesity and light exposure at night [8]. Moreover, in vivo study with mice exposed to light at night demonstrated more weight gain and impaired glucose tolerance [5]. Cognitive impairment and mood disorder can be induced by ALAN due to excessive sleepiness at daytime and mood changes associated with sleep deprivation [9-11]. In addition, ALAN can increase risk of cancers such as breast, prostate, and colorectal cancers [12-15]. These adverse health effects are related with inhibition of night time secretion of melatonin induced by circadian disruption [16].

Common situation to expose to ALAN and disrupt circadian rhythm is shift work and about $15 \%-25 \%$ of people worked at night in modern world [17-19]. Shift workers experience more sleep deprivation, sleepiness, and insomnia and these sleep problems decrease working performance and increase errors and accidents. Moreover, health problems such as cognitive impairment, depression, metabolic diseases, cardiovascular diseases, and cancers comparing with nonshift workers [20]. Therefore, it is important to prevent and treat health problems associated with ALAN for shift workers.

Micturition is influenced by circadian rhythm and voiding dysfunction can be induced by circadian disruption. For example, nocturia is voiding dysfunction that people wake up to urinate during sleep and nocturia is induced by impairment of circadian antidiuretic hormone release and abnormal urine production at night. Decreased bladder capacity noted in people with abnormal sleep pattern is one of reason to induce nocturia compared with people with normal sleep pattern [21]. Therefore, people in shift work can experience voiding problems associated with circadian disruption and abnormal voiding is important risk factor to reduce well-being. However, concern about abnormal voiding is insufficient compared with other health issues associated with shift workers. This review explores voiding dysfunction found in shift workers based on investigational and clinical studies.

\section{ROLE OF CLOCK GENE IN THE BLADDER}

Circadian rhythm is controlled by master circadian clock, located in the suprachiasmatic nucleus (SCN) of the hypothalamus and circadian clock oscillations, at the molecular level, are governed by transcription-translation feedback loops. The feedback loop is consisted of core clock genes such as circadian transcription factor complex (CLOCK) and brain and muscle Arnt-like 1 (BMAL1) that positively interacts with the promoters of clock-controlled genes and proteins period (Per) and cryptochrome like protein (Cry) that inhibit their own transcription by interacting with the CLOCK/BMAL1 complex $[22,23]$. Moreover, molecular clock is existed in the various peripheral organs and coordination between central clock in SCN and peripheral clock in each organ maintains physiological function [24].

Normal voiding is influenced by urine production of the kidney and urine storage of the bladder and changes of production and storage of urine are regulated by circadian control. Increased plasma vasopressin modulated by central circadian clock at late sleep period reduces urine production by water reabsorption and electrolyte in the kidney. There are animal studies to show that how circadian disruption influence urine production of the kidney at molecular level. A study using Clock knockout mice showed that loss of circadian rhythm of renal sodium excretion and plasma aldosterone level [25]. Noh et al. [26] reported that mice deficient in Per1 and Per2 lost diurnal changes of urine volume compared with wild type mice. In addition, there are studies to show existence of clock genes in the bladder. Multiple genetic oscillators such as Per1, Bmal1, and Rev-erb $\alpha$ were found in the bladder and expression of clock genes were influenced by light-dark cycle. A recent study in CLOCK gene mutant mice showed that increased number of voiding and urine volume during sleep phase compared with wild type mice [27]. These findings meant that CLOCK gene deficiency in both of the bladder and kidney by decreased storage function of the bladder and increased urine production of the kidney at night.

These findings proved the existence of peripheral clock in the bladder and, therefore; the next step is to identify the actual role of clock gene in the storage function of the bladder. Storage function of the bladder is regulated by contraction and relaxation of bladder smooth muscle and various factors are involved in increase or decrease of bladder capacity [28]. Moreover, diurnal changes of contractile properties of the bladder smooth muscle was noted [29]. Negoro et al. [30] found diurnal variation of connexin 43 (Cx43) of the bladder smooth muscle and involvement of peripheral clock in the bladder. They focused on $\mathrm{Cx} 43$ because several studies showed that $\mathrm{Cx} 43$ was a gap junction protein existed in the bladder smooth muscle and was associated with bladder contraction. Gap junctions composed of Cx43 enables cell-to-cell signaling. Therefore, in- 
creased cell-to-cell signaling through gap junctions containing $\mathrm{Cx} 43$ induces intercellular electrical signaling and these changes can produce conditions such as overactive bladder (OAB) that decreased storage function of the bladder [31-33]. According to the results by Negoro et al. [30], diurnal variation of $\mathrm{Cx} 43$ in the bladder smooth muscle is coordinated with circadian clock of the bladder. Thus, diurnal variation of $\mathrm{Cx} 43$ associated with clock gene may contribute increased bladder capacity during sleep and it enhances bladder storage function to prevent nocturia at night.

Urothelium, mucosal layer of the bladder, also plays a role to control storage function of the bladder. Urothelium is the first tissue to sense bladder extension when the bladder is filled with urine and activation of afferent pathway transmits signals in response to stretch of the bladder wall. These afferent signals induce bladder contraction and reduce bladder capacity [34,35]. Based on this role of urothelium, there is a recent study to find the association of mechanosensor of urothelium and circadian clock. After bladder extension, mechanosensors of the urothelium induce releasing neurotransmitters, adenosine triphosphate (ATP). Mechanosensors in urothelium such as transient receptor potential cation channel subfamily V member 4 (TRPV4) and Piezol1 trigger ATP release in response to the bladder expansion [36-38]. Also, vesicular nucleotide transporter (VNUT) and gap junction composed of connexin 26 (Cx26) in urothelium plays a role in ATP release $[33,39,40]$. Ihara et al. [41] showed diurnal changes of urothelial mechanosensors (TRPV4 and Piezol1), VNUT, and Cx26 that increased during the active period and decreased during the sleep period. These changes were coordinated with the diurnal expression of clock gene of the urothelium. However, not only the disruption of clock gene expression but also loss of diurnal changes of mechanosensors, VNUT, and Cx26 were observed in mice deficient with clock gene. Therefore, mice deficient with clock gene showed increased sense of the bladder extension and their bladder capacity during sleep period was decreased compared with normal mice. And this hypersensitivity to bladder extension due to disruption of circadian rhythm may reduce storage function of the bladder and induce nocturia.

\section{CHANGE OF VOIDING PATTERN IN SHIFT WORKERS}

Although it is well known that urine production and bladder capacity are influenced by circadian rhythm, studies about the prevalence and characteristics of voiding problems in shift workers are insufficient. Previous studies revealed that nurses often experienced voiding dysfunction such as nocturia, $\mathrm{OAB}$ and urinary incontinence (UI) compared with general population. And they found that voiding dysfunction is an important factor to reduce quality of life (QoL) and productivity at working place $[42,43]$. However, the previous investigators did not focus on the influence of circadian disruption. Instead, they concluded that voiding dysfunction was resulted from occupational stress and inconvenient environment to induce poor bladder habits. A recent study also showed that severe UI was associated with intentions to stop in nurses and midwifes, however; relationship between circadian disruption and severe UI could not analyzed because the study included workers for part-time or days only (not shifts) [44]. In general, most of the studies about the prevalence, impact, and cause of voiding dysfunction in working population seem to be lack of quality because they usually included only women and there were no occupational diversities [45].

There were 2 recent prospective studies to investigate voiding patterns in shift workers. Kim et al. [46] compared voiding patterns between nurses worked as rotational shifts and regular daytime. Comparing with nurses with regular daytime, nurses worked as rotational shifts showed increased urine volume per day (both day and night) and mean voiding volume was significantly increased during night shift. Moreover, nocturia was increased during night shift. After return to day shift, urine volume was decreased, however; urine volume at night was not decreased and nocturia was not improved. These findings showed that circadian disruption due to shift work induced urine production at night and nocturia. However, the limitation of the report by Kim et al. [46] was small number of participants (nurses worked as rotational shift: $\mathrm{n}=19$ and nurses worked as regular daytime: $n=7$ ). Later, the other study including large number of shift workers ( $n=365 ; 200$ males, 165 females) analyzed the effect of circadian disruption on nocturia [47]. The number of nocturia was higher in night-shift workers compared with nonshift workers. Urine volume at night of night-shift workers was not significantly different from nonshift workers. However, significantly reduced functional bladder capacity was observed in night-shift workers. Thus, the author suggested that nocturia of night-shift workers was induced by decreased storage function of the bladder rather than increased urine production at night. Although functional bladder capacity between nurses worked as rotational shift and regular day- 
time was not significantly different from the study by Kim et al. [46], similar change of the mean voided volume reflecting decreased storage function of the bladder at night was observed in

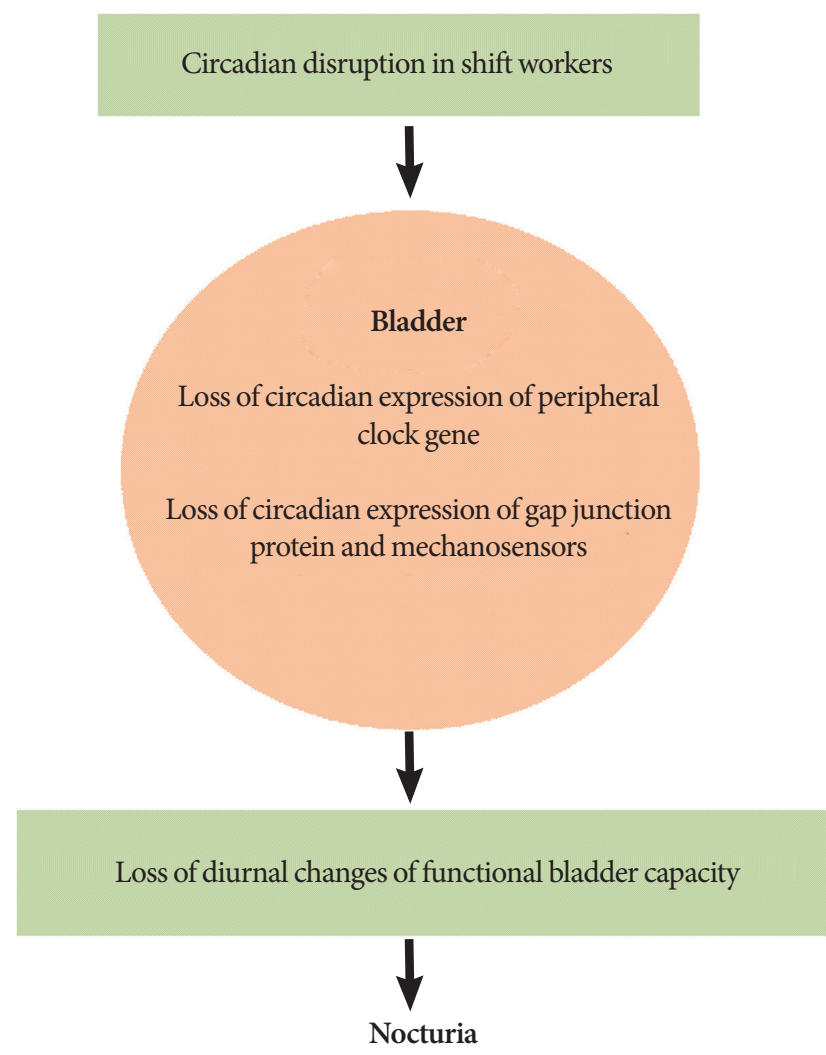

Fig. 1. Nocturia associated with circadian change of storage function of the bladder. rotational-shift nurses. However, in case we focused functional bladder capacity during night time, nurses worked as rotational shift showed significantly decreased functional bladder capacity during night shift compared with day shift. Therefore, circadian disruption in shift workers induces nocturia by increased urine production of the kidney and decreased storage function of the bladder (Fig. 1).

Underlying mechanism to induce voiding dysfunction observed in the shift workers is different from others, however, shift workers with voiding problem showed common symptoms such as frequent urination, urge to void, and nocturia. Therefore, general approach for the diagnosis and treatment of voiding dysfunction can be applied for the shift workers (Fig. 2) [48-53].

\section{SUMMARY AND CONCLUSIONS}

Micturition is a human behavior closely associated with circadian rhythm and several recent studies showed the existence of peripheral clock in the bladder and their role in the control of bladder function. However, well-designed clinical study to present the prevalence, impact, and characteristics observed in shift workers are lacking comparing the importance of voiding dysfunction associated with circadian disruption. Moreover, at present, there are studies concerning only nocturia of shift workers and attention about voiding patterns of daytime has been relatively insufficient. Therefore, further well-designed clinical studies are necessary to understand circadian disrup-

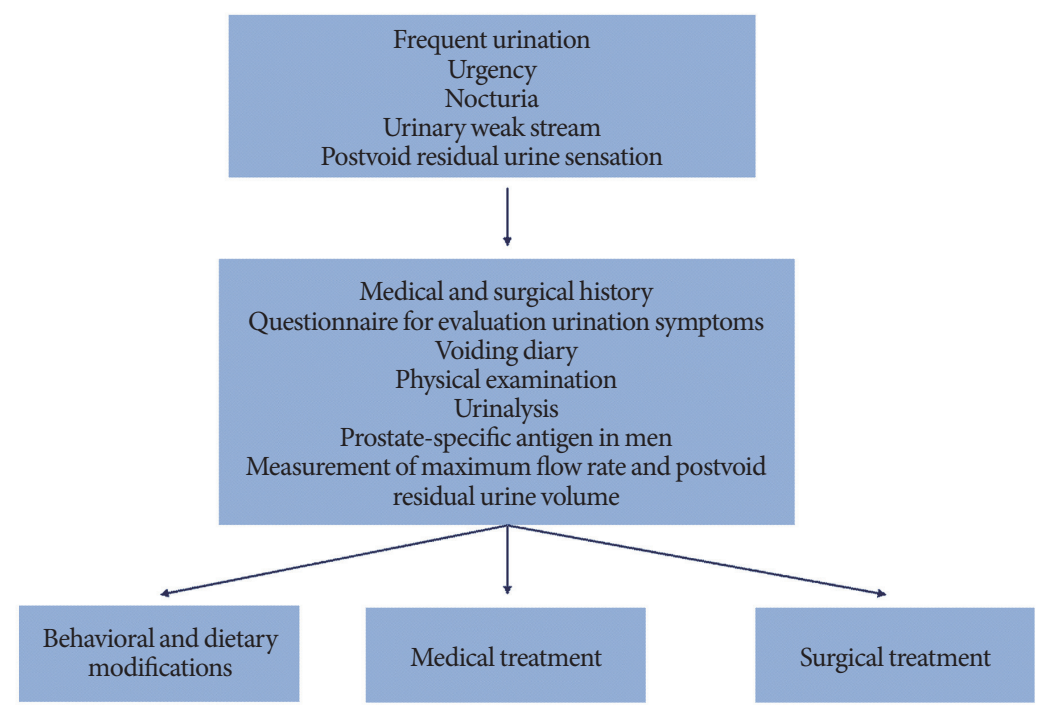

Fig. 2. Diagnosis and treatment of voiding dysfunction. 
tion associated voiding problems and improve QoL of shift workers experiencing voiding dysfunction.

\section{AUTHOR CONTRIBUTION STATEMENT}

- Full access to all the data in the study and takes responsibility for the integrity of the data and the accuracy of the data analysis: $K H K$, SJK

- Study concept and design: SJK, KHK

- Acquisition of data: JWK, YSC

- Analysis and interpretation of data: SJK, JWK

- Drafting of the manuscript: SJK

- Critical revision of the manuscript for important intellectual content: $H N Y$

- Obtained funding: SJK, KJC, KHK

- Administrative, technical, or material support: JWK, YSC

- Study supervision: $K H K$

\section{REFERENCES}

1. Garstang RH. Night-sky brightness at observatories and sites. Publ Astron Soc Pac 1989;101:306-29.

2. Cinzano P, Falchi F, Elvidge CD, Baugh KE. The artificial night sky brightness mapped from DMSP satellite Operational Linescan System measurements. Mon Not R Astron Soc 2000;318:641-57.

3. Smith M. Time to turn off the lights. Nature 2009;457:27.

4. Touitou Y, Reinberg A, Touitou D. Association between light at night, melatonin secretion, sleep deprivation, and the internal clock: health impacts and mechanisms of circadian disruption. Life Sci 2017;173:94-106.

5. Fonken LK, Workman JL, Walton JC, Weil ZM, Morris JS, Haim A, et al. Light at night increases body mass by shifting the time of food intake. Proc Natl Acad Sci U S A 2010;107:18664-9.

6. Bedrosian TA, Fonken LK, Walton JC, Nelson RJ. Chronic exposure to dim light at night suppresses immune responses in Siberian hamsters. Biol Lett 2011;7:468-71.

7. LeGates TA, Altimus CM, Wang H, Lee HK, Yang S, Zhao H, et al. Aberrant light directly impairs mood and learning through melanopsin-expressing neurons. Nature 2012;491:594-8.

8. McFadden E, Jones ME, Schoemaker MJ, Ashworth A, Swerdlow AJ. The relationship between obesity and exposure to light at night: cross-sectional analyses of over 100,000 women in the Breakthrough Generations Study. Am J Epidemiol 2014;180:245-50.

9. Vallières A, Azaiez A, Moreau V, LeBlanc M, Morin CM. Insomnia in shift work. Sleep Med 2014;15:1440-8.
10. Kalmbach DA, Pillai V, Cheng P, Arnedt JT, Drake CL. Shift work disorder, depression, and anxiety in the transition to rotating shifts: the role of sleep reactivity. Sleep Med 2015;16:1532-8.

11. Lee HY, Kim MS, Kim O, Lee IH, Kim HK. Association between shift work and severity of depressive symptoms among female nurses: the Korea Nurses' Health Study. J Nurs Manag 2016;24:192200.

12. Travis RC, Balkwill A, Fensom GK, Appleby PN, Reeves GK, Wang XS, et al. Night shift work and breast cancer incidence: three prospective studies and meta-analysis of published studies. J Natl Cancer Inst 2016 Oct 6;108(12). pii: djw169. Print 2016 Dec.

13. Kubo T, Ozasa K, Mikami K, Wakai K, Fujino Y, Watanabe Y, et al. Prospective cohort study of the risk of prostate cancer among rotating-shift workers: findings from the Japan collaborative cohort study. Am J Epidemiol 2006;164:549-55.

14. Schernhammer ES, Laden F, Speizer FE, Willett WC, Hunter DJ, Kawachi I, et al. Night-shift work and risk of colorectal cancer in the nurses' health study. J Natl Cancer Inst 2003;95:825-8.

15. Parent MÉ, El-Zein M, Rousseau MC, Pintos J, Siemiatycki J. Night work and the risk of cancer among men. Am J Epidemiol 2012; 176:751-9.

16. de Seze R, Ayoub J, Peray P, Miro L, Touitou Y. Evaluation in humans of the effects of radiocellular telephones on the circadian patterns of melatonin secretion, a chronobiological rhythm marker. J Pineal Res 1999;27:237-42.

17. McMenamin T, Holden R, Bahls D. A time to work: recent trends in shift work and flexible schedules. Mon Lab Rev 2007;130:3-14.

18. Boisard P, Cartron D, Gollac M, Valeyre A. Time and work: duration of work. Luxembourg: Publications Office of the European Union; 2003.

19. Messenger JC, Lee S, McCann D. Working time around the world: trends in working hours, laws, and policies in a global comparative perspective. New York: Routledge; 2007.

20. Costa G. Shift work and health: current problems and preventive actions. Saf Health Work 2010;1:112-23.

21. Weiss JP, Blaivas JG, Stember DS, Chaikin DC. Evaluation of the etiology of nocturia in men: the nocturia and nocturnal bladder capacity indices. Neurourol Urodyn 1999;18:559-65.

22. Gekakis N, Staknis D, Nguyen HB, Davis FC, Wilsbacher LD, King DP, et al. Role of the CLOCK protein in the mammalian circadian mechanism. Science 1998;280:1564-9.

23. Kume K, Zylka MJ, Sriram S, Shearman LP, Weaver DR, Jin X, et al. mCRY1 and mCRY2 are essential components of the negative limb of the circadian clock feedback loop. Cell 1999;98:193-205.

24. Noh JY, Han DH, Yoon JA, Kim MH, Kim SE, Ko IG, et al. Circa- 
dian rhythms in urinary functions: possible roles of circadian clocks? Int Neurourol J 2011;15:64-73.

25. Trudel E, Bourque CW. Circadian modulation of osmoregulated firing in rat supraoptic nucleus neurones. J Neuroendocrinol 2012; 24:577-86.

26. Noh JY, Han DH, Kim MH, Ko IG, Kim SE, Park N, et al. Presence of multiple peripheral circadian oscillators in the tissues controlling voiding function in mice. Exp Mol Med 2014;46:e81.

27. Ihara T, Mitsui T, Nakamura Y, Kira S, Miyamoto T, Nakagomi H, et al. The Clock mutant mouse is a novel experimental model for nocturia and nocturnal polyuria. Neurourol Urodyn 2017;36:10348.

28. Fowler CJ, Griffiths D, de Groat WC. The neural control of micturition. Nat Rev Neurosci 2008;9:453-66.

29. White RS, Zemen BG, Khan Z, Montgomery JR, Herrera GM, Meredith AL. Evaluation of mouse urinary bladder smooth muscle for diurnal differences in contractile properties. Front Pharmacol 2015;5:293.

30. Negoro H, Kanematsu A, Doi M, Suadicani SO, Matsuo M, Imamura $\mathrm{M}$, et al. Involvement of urinary bladder Connexin 43 and the circadian clock in coordination of diurnal micturition rhythm. Nat Commun 2012;3:809.

31. Miyazato M, Sugaya K, Nishijima S, Kadekawa K, Machida N, Oshiro $\mathrm{Y}$, et al. Changes of bladder activity and connexin 43-derived gap junctions after partial bladder-outlet obstruction in rats. Int Urol Nephrol 2009;41:815-21.

32. Song SH, Joo HT, Cho HW, Hwang HW, Lee KH, Kim DK. Sexand age-related changes in connexin 43 expression in normal rat bladder. Int Neurourol J 2011;15:25-8.

33. Kim SJ, Park EY, Hwang TK, Kim JC. Therapeutic effects of connexin inhibitors on detrusor overactivity induced by bladder outlet obstruction in rats. Urology 2011;78:475.e1-7.

34. Keay SK, Birder LA, Chai TC. Evidence for bladder urothelial pathophysiology in functional bladder disorders. Biomed Res Int 2014;2014:865463.

35. Birder LA. Urinary bladder, cystitis and nerve/urothelial interactions. Auton Neurosci 2014;182:89-94.

36. Mochizuki T, Sokabe T, Araki I, Fujishita K, Shibasaki K, Uchida K, et al. The TRPV4 cation channel mediates stretch-evoked Ca2+ influx and ATP release in primary urothelial cell cultures. J Biol Chem 2009;284:21257-64.

37. Miyamoto T, Mochizuki T, Nakagomi H, Kira S, Watanabe M, Takayama Y, et al. Functional role for Piezol in stretch-evoked $\mathrm{Ca}^{2+}$ influx and ATP release in urothelial cell cultures. J Biol Chem 2014;289:16565-75.
38. Coste B, Mathur J, Schmidt M, Earley TJ, Ranade S, Petrus MJ, et al. Piezo1 and Piezo2 are essential components of distinct mechanically activated cation channels. Science 2010;330:55-60.

39. Nakagomi H, Yoshiyama M, Mochizuki T, Miyamoto T, Komatsu $\mathrm{R}$, Imura $\mathrm{Y}$, et al. Urothelial ATP exocytosis: regulation of bladder compliance in the urine storage phase. Sci Rep 2016;6:29761.

40. Haefliger JA, Tissières P, Tawadros T, Formenton A, Bény JL, Nicod P, et al. Connexins 43 and 26 are differentially increased after rat bladder outlet obstruction. Exp Cell Res 2002;274:216-25.

41. Ihara T, Mitsui T, Nakamura Y, Kira S, Nakagomi H, Sawada N, et al. Clock genes regulate the circadian expression of Piezol, TRPV4, Connexin26, and VNUT in an ex vivo mouse bladder mucosa. PLoS One 2017;12:e0168234.

42. Liao YM, Yang CY, Kao CC, Dougherty MC, Lai YH, Chang Y, et al. Prevalence and impact on quality of life of lower urinary tract symptoms among a sample of employed women in Taipei: a questionnaire survey. Int J Nurs Stud 2009;46:633-44.

43. Zhang C, Hai T, Yu L, Liu S, Li Q, Zhang X, et al. Association between occupational stress and risk of overactive bladder and other lower urinary tract symptoms: a cross-sectional study of female nurses in China. Neurourol Urodyn 2013;32:254-60.

44. Pierce H, Perry L, Gallagher R, Chiarelli P. Urinary incontinence, work, and intention to leave current job: a cross sectional survey of the Australian nursing and midwifery workforce. Neurourol Urodyn 2017;36:1876-83.

45. Pierce H, Perry L, Chiarelli P, Gallagher R. A systematic review of prevalence and impact of symptoms of pelvic floor dysfunction in identified workforce groups. J Adv Nurs 2016;72:1718-34.

46. Kim KT, Kim CH, Kwon B, Han DH, Yoon SJ, Cho S, et al. Do rotational shifts affect micturition patterns in real practice? A pilot study in healthy, young female nurses. Int Neurourol J 2014;18:20612.

47. Kim JW. Effect of shift work on nocturia. Urology 2016;87:153-60.

48. Takahashi S, Takei M, Nishizawa O, Yamaguchi O, Kato K, Gotoh $\mathrm{M}$, et al. Clinical guideline for female lower urinary tract symptoms. Low Urin Tract Symptoms 2016;8:5-29.

49. Homma Y, Gotoh M, Kawauchi A, Kojima Y, Masumori N, Nagai A, et al. Clinical guidelines for male lower urinary tract symptoms and benign prostatic hyperplasia. Int J Urol 2017;24:716-29.

50. Groen J, Pannek J, Castro Diaz D, Del Popolo G, Gross T, Hamid R, et al. Summary of European Association of Urology (EAU) Guidelines on Neuro-Urology. Eur Urol 2016;69:324-33.

51. Kim SJ, Shin IS, Eun SJ, Whangbo TK, Kim JW, Cho YS, et al. Evidence is enough?: A systematic review and network meta-analysis of the efficacy of tamsulosin $0.2 \mathrm{mg}$ and tamsulosin $0.4 \mathrm{mg}$ as an 
initial therapeutic dose in asian benign prostatic hyperplasia patients. Int Neurourol J 2017;21:29-37.

52. Choo MS, Yoo C, Cho SY, Jeong SJ, Jeong CW, Ku JH, et al. Development of decision support formulas for the prediction of bladder outlet obstruction and prostatic surgery in patients with lower urinary tract symptom/benign prostatic hyperplasia: part I, development of the formula and its internal validation. Int Neurourol J
2017;21(Suppl 1):S55-65.

53. Chuang FC, Hsiao SM, Kuo HC. The overactive bladder symptom score, international prostate symptom score-storage subscore, and urgency severity score in patients with overactive bladder and hypersensitive bladder: which scoring system is best? Int Neurourol J 2018;22:99-106. 